\section{Commentary: Superior vena cava reconstruction techniques}

\author{
Nathan Haywood, MD, and Irving L. Kron, MD
}

Honda and colleagues ${ }^{1}$ present a report on the repair of a large superior vena cava (SVC) aneurysm using an autologous pericardial patch. ${ }^{1}$ The group demonstrated an excellent outcome for a complex problem. Although large aneurysms of the SVC are quite rare, there are a number of more common indications for resection and subsequent reconstruction, including malignant invasion from the lung or from tumors arising from anterior mediastinum. We read this contribution with interest because it adds to the larger discussion surrounding techniques for SVC reconstruction.

The decision to proceed with either patch repair or replacement is best described for SVC syndrome secondary to malignant invasion. Traditionally, if resection $>30 \%$ to $50 \%$ of the circumference is required, SVC replacement is preferred over patch repair due to the risk of narrowing the lumen or kinking with a larger patch. ${ }^{2,3}$ In our experience, if only the anterior portion of the SVC is involved or abnormal and the posterior wall can be preserved, patch repair can be successfully implemented. Undoubtedly, the anatomic considerations for repair of the giant SVC aneurysm treated in this report are unique. A question for the authors would be whether resection and replacement were considered as an alternative to patch repair given the abnormal aneurysmal thinning of the anterior, lateral, and posterior walls.

There are a number of biologic and artificial conduits available for SVC reconstruction. Prosthetic polytetrafluoroethylene has been used successfully ${ }^{4}$; however, patients are often subject to continued anticoagulation

\footnotetext{
From the Division of Thoracic and Cardiovascular Surgery, Department of Surgery, University of Virginia, Charlottesville, Va.

Disclosures: The authors reported no conflicts of interest.

The Journal policy requires editors and reviewers to disclose conflicts of interest and to decline handling or reviewing manuscripts for which they may have a conflict of interest. The editors and reviewers of this article have no conflicts of interest.

Received for publication Oct 21, 2020; revisions received Oct 21, 2020; accepted for publication Oct 23, 2020; available ahead of print Oct 29, 2020.

Address for reprints: Irving L. Kron, MD, Division of Thoracic and Cardiovascular Surgery, Department of Surgery, University of Virginia, 1215 Lee St, PO Box 800679, Charlottesville, VA 22908 (E-mail: ILK@virginia.edu).

JTCVS Techniques 2020;4:187-8

2666-2507

Copyright (C) 2020 The Authors. Published by Elsevier Inc. on behalf of The American Association for Thoracic Surgery. This is an open access article under the CC BY-NCND license (http://creativecommons.org/licenses/by-nc-nd/4.0/).

https://doi.org/10.1016/j.xjtc.2020.10.040
}

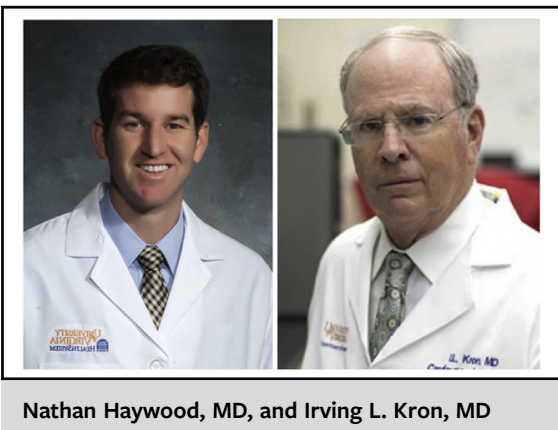

\section{CENTRAL MESSAGE \\ Continued investigation into the techniques of superior vena cava reconstruction is paramount and should prioritize minimizing the risk of future thrombosis or me- chanical obstruction.}

therapy to prevent future thrombosis. Similar to Honda and colleagues, ${ }^{1}$ our preference is biologic tissue replacement, which may be utilized for either a patch repair or replacement conduit if tubularized. Autologous pericardium, implemented by the authors in the present study, is an effective approach. The authors note this strategy was the preference of the patient. We like to use bovine pericardium, which avoids pericardiectomy and has the benefit of various large sizing options. Long-term patency rates following SVC resection and reconstruction with bovine pericardium are high. ${ }^{5}$ There are various, less commonly used conduits for replacement, including spiral vein grafts and a number of different vascular homografts.

We congratulate the authors on their detailed description of a giant SVC aneurysm repair. Although a rare condition, the techniques detailed add to the larger discussion surrounding SVC reconstruction. Continued investigation of this topic is paramount and should prioritize minimizing risk of future thrombosis or mechanical obstruction. The use of a biologic conduit may aid in this pursuit.

\section{References}

1. Honda K, Yuzaki M, Fujimoto T, Nishimura Y. Reconstruction of the superior vena cava with an autologous pericardial patch for a giant superior vena cava aneurysm. J Thorac Cardiovasc Surg Tech. 2020;4:183-6.

2. Maurizi G, Poggi C, D’Andrilli A, Vanni C, Ciccone AM, Ibrahim M, et al Superior vena cava replacement for thymic malignancies. Ann Thorac Surg. 2019;107:386-92.

3. Lee DS, Flores RM. Superior vena caval resection in lung cancer. Thorac Surg Clin. 2014;24:441-7. 
4. Sekine Y, Suzuki H, Saitoh Y, Wada H, Yoshida S. Prosthetic reconstruction of the superior vena cava for malignant disease: surgical techniques and outcomes. Ann Thorac Surg. 2010;90:223-8.
5. D'Andrilli A, De Cecco CN, Maurizi G, Muscogiuri G, Baldini R, David V, et al Reconstruction of the superior vena cava by biologic conduit: assessment of longterm patency by magnetic resonance imaging. Ann Thorac Surg. 2013;96:1039-45. 